\title{
Microsurgical Reconstruction of Traumatic Lower Extremity Defects in Pediatric Patients: Is Fasciocutanous Flap A Versatile Tool to Replace Musculocutaneous Flap?
}

\author{
WAEL AYAD, M.D.; MOHAMMAD EL-GAMMAL, M.B.B.Ch.; AYMAN FARAHAT, M.D. and \\ AMR EL-BATAWY, M.D. \\ The Department of Plastic, Reconstructive and Burn Surgery, Faculty of Medicine, Al-Azhar University
}

\begin{abstract}
The purpose of this report is to evaluate the outcome of microsurgical reconstruction of traumatic lower extremity defects in children and compare fasiocutenous flaps with muscle and musculocutaneous flaps. At Al-Azhar University Hospitals (Al-Hussien and Sayed Galal Hospitals) in the last two years. 50 free tissue transfers had been performed in 50 children. Patients ranged in age from 3 to 16 years old, The defect location included the dorsum of foot in 24 cases, medial aspect of foot in 4 cases, lateral aspect of foot in one case, forefoot in 2 cases, heel in 5 cases, ankle in one case, upper third of leg in 3 cases, middle third of leg in 6 cases, lower third of leg in 4 cases and the knee in 2 cases. Flaps used in this study were myocutenous and muscle flaps (L.D and R.F) in 38 cases, fasciocutenous flaps (A.L.T) in 7 cases, and chiemeric flap (L.D+S.A) in 5 cases. Hospital stay was ranged from 5 days to 14 days with an average of 8.8 days. The recipient's vessels were anterior tibial vessels in 38 cases, posterior tibial vessels in 7 cases, femoral vessels in 2 cases, dorsalis pedis vessels in 2 cases, and popliteal vessels in one case. The postoperative complications were seen in 13 patients in the form of venous congestion in three cases, superficial infection in five patients, delayed wound healing in three patients, partial necrosis in one case, graft loss in one case, with total flap loss in three cases. One could conclude from our report that a free fasciocutaneous flap is an excellent option for lower extremity reconstruction. Our data indicate that it can be successfully used in all clinical settings, without outcomes equivalent to the more traditional muscle flap.
\end{abstract}

Key Words: Lower extremity reconstruction - Anterolateral thigh flap - Free flap in children - Pediatric microsurgery - Muscle flap.

\section{INTRODUCTION}

Free-tissue transfers gain increasing popularity for reconstruction of various defects, as a result of continuing advances in microsurgical technique [2].

Microsurgical lower extremity reconstruction of traumatic defects is the most challenging tasks in pediatric microsurgery [8].
The major advantage of free tissue transfer in children is the ability to reconstruct defects in a single stage [1].

With present-day technology, we advocate for using the "reconstructive elevator" and bypass more traditional techniques for the benefits of free tissue transfer in children, allowing for singlestage reconstruction and in many cases primary closure of the donor site [6].

\section{PATIENTS AND METHODS}

A retrospective review was conducted of all pediatric patients underwent microsurgical free tissue transfer for post-traumatic lower limb reconstruction (patients younger than 17 years of age) at the Al-Azhar University Hospitals (Al-Hussien and Said Galal Hospitals) from July 2015 to June 2017. Free flaps performed for conditions other than trauma were excluded. Demographic data of the patients including age, sex, defect location, flap and flap type, recipient vessels, use of vein graft, operative time in minutes, length of hospital stay in days and complications, flaps used were collected in the Table (1).

Table (1): Choice of flap type.

\begin{tabular}{lc}
\hline Flap type & No. of patients \\
\hline Muscle: & 37 \\
Latissimus Dorsi & 5 \\
Chiemeric (L.D+S.A) & 1 \\
Rectus femoris & \\
Fasciocutenous: & 7 \\
Anterolateral thigh & \\
\hline
\end{tabular}




\section{RESULTS}

Over a period of two years, 50 free flaps were used for reconstruction of post-traumatic defects in the lower limb of 50 patients, the study included 17 females and 37 males, Patient's age ranged between 3 and 16 years old with average 9.46 . The mechanisms of injury were a motor car accident, lawnmower, falling from a height and crushing injury.

The defect location included the dorsum of foot in 24 cases, medial aspect of foot in 4 cases, lateral aspect of foot in one case, forefoot in 2 cases, heel in 5 cases, ankle in one case, upper third of leg in 3 cases, middle third of leg in 6 cases, lower third of leg in 4 cases and the knee in 2 cases. Flaps used in this study were myocutenous and muscle flaps (L.D and R.F) in 38 cases, fasciocutenous flaps (A.L.T) in 7 cases, and chiemeric flap (L.D+S.A) in 5 cases.

The recipient's vessels were anterior tibial vessels in 38 cases, posterior tibial vessels in 7 cases, femoral vessels in 2 cases, dorsalis pedis vessels in 2 cases, and popliteal vessels in one case.

We used the A-V loop as a vein graft in three cases, the operative time ranged from 6 hours to 8.6 hours with an average of 7.23 hours. The length of hospital stay ranged from 5 days to 14 days with an average of 8.8 days.

The postoperative complications were seen in 13 patients in the form of venous congestion in three cases, superficial infection in five patients, delayed wound healing in three patients, partial necrosis in one case, graft loss in one case, with total flap loss in three cases.

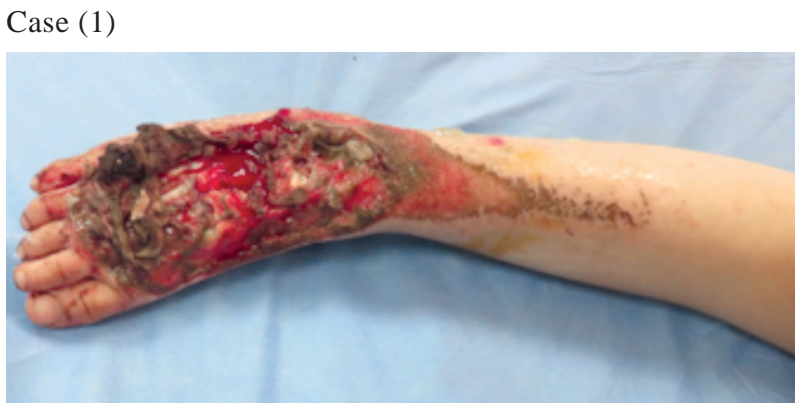

Fig. (1): Case of a female patient 9 years old presented with a traumatic defect on the dorsum of the right foot.

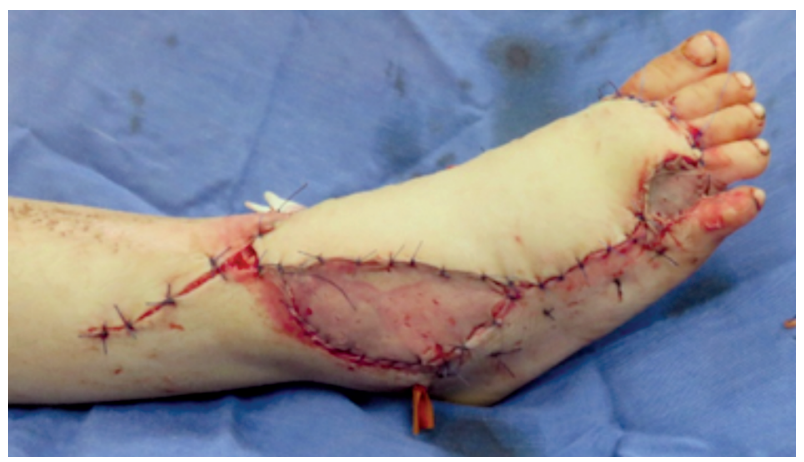

Fig. (2): Harvesting and insetting of the L.D myocutenous flap.

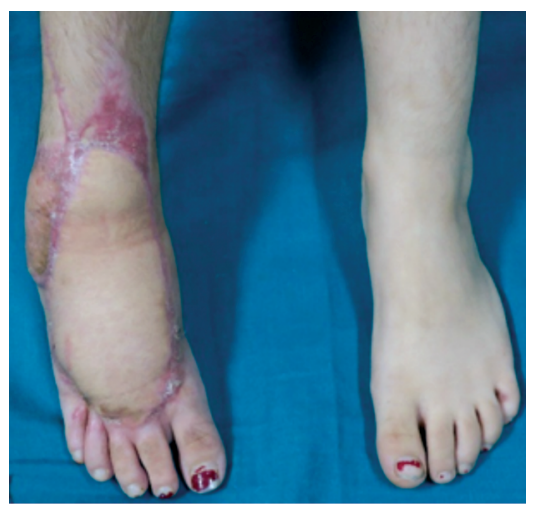

Fig. (3): A Few months later after complete healing of the flap and the child could walk.

Case (2)

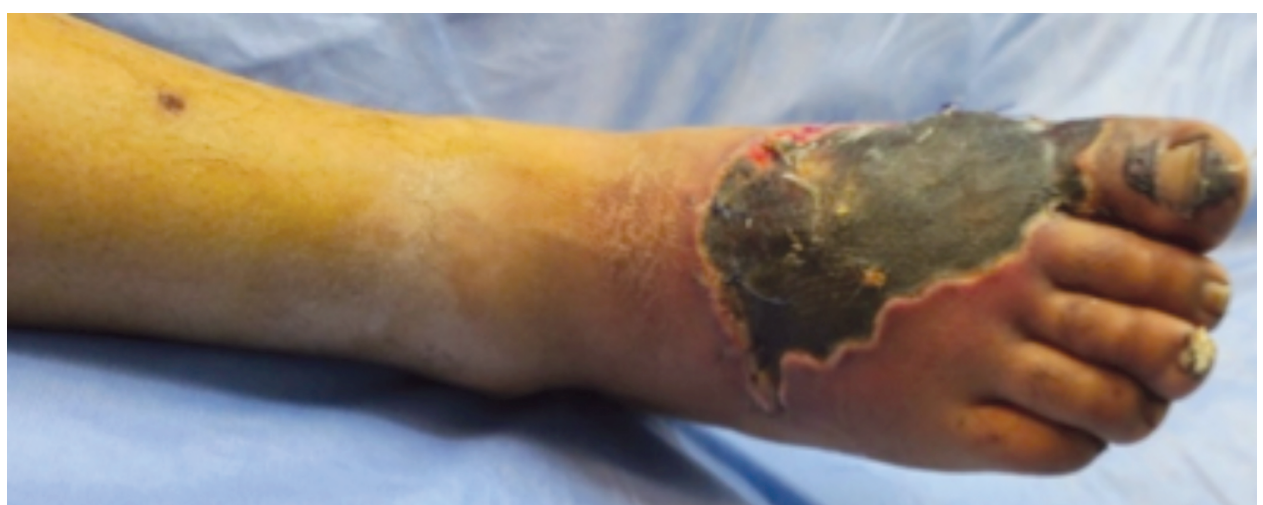

Fig. (4): The case of a male patient 15 years old presented with post-traumatic eschar on the dorsum of the right foot. 

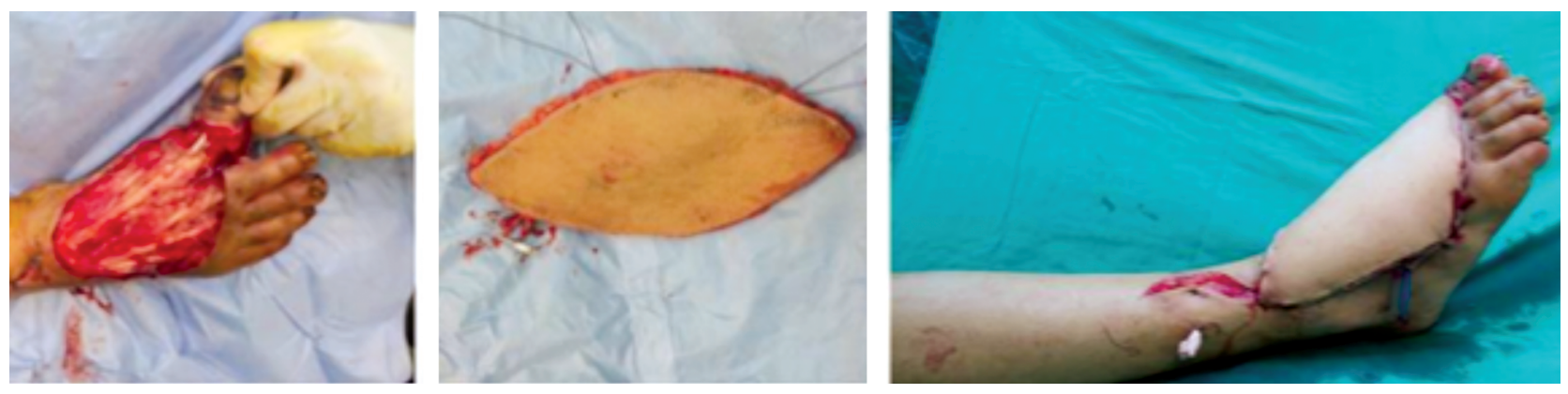

Fig. (5): Harvesting and insetting of the A.L.T flap.

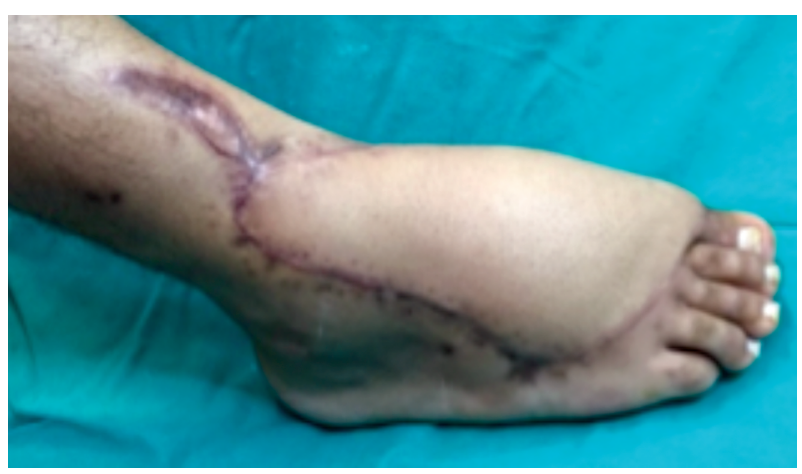

Fig. (6): A Few months later after complete recovery and during physiotherapy.

\section{DISCUSSION}

Reconstruction of the lower extremity can be a challenging task. The technical aspects of free tissue transfer can be further complicated by available donor site vessels (which may have been injured in the initial trauma), gravitational forces, complex underlying bony fractures, need for weight-bearing, and the contour of the defect on a cylindrical limb. Size and location of the defect, as well as donor site morbidity, must be taken into consideration when planning a reconstruction [15].

There are certain benefits to muscle flaps that can easily obliterate dead space and can conform well to the unique contour of the lower extremity. The pliability of the anterolateral thigh flap can make draping more difficult in certain lower extremity wounds [15].

The treatment choice for soft tissue defects of the lower extremity depends on the size and location of the wound, besides its cause. When a functional transfer is desirable, a muscle flap is the only reasonable reconstruction. Conversely, in the presence of osteomyelitis, exposed hardware, or open fracture, both fasciocutaneous and muscle flap are feasible options [14].

Early in this series the L.D muscle or myocutenous flap was our main choice in reconstruction of pediatric lower limb defects, either as a single or as a chimeric with serratus muscle flap, the muscle flap carries the advantage of long pedicle, larger vessel diameter and its popularity with a short learning curve, later in the study, we started to harvest the A.L.T flap as our best choice in pediatric lower limb reconstruction, it offers the advantage of being less bulky with more cosmetic outcome, and less donor site morbidity.

Elgammal et al., reported 42 children with traumatic ankle and foot defects that reconstructed by A.L.T fasciocutenous flap. Also, Namdar et al reported 14 children with lower limb defect after the trauma that reconstructed by L.D muscle flap.

Notably, there was no difference in major or minor complication rate between flap type chosen in our series.

\section{Conclusion:}

A free fasciocutaneous flap is an excellent option for lower extremity reconstruction. Our data indicate that it can be successfully used in all clinical settings, without outcomes equivalent to the more traditional muscle flap.

Finally, in our series, we conclude that fasciocutenous flap (A.L.T) is a versatile tool as well as a musculocutaneous flap (L.D) in pediatric lower extremity reconstruction.

\section{REFERENCES}

1- Aboelatta Y.A. and Aly H.M.: Free tissue transfer and replantation in pediatric patients: Technical feasibility and outcome in a series of 28 patients. J. Hand Microsurg., 5: 74-80, 2013.

2- Acar M.A., Güleç A., Aydin B.K., Erkoçak F., Yilmaz G. and Şenaran H.: Reconstruction of foot and ankle defects with a free anterolateral thigh flap in pediatric patients. J. Reconstr. Microsurg., 31: 225-232, 2015.

3- Arnez Z.M. and Hanel D.P.: Free tissue transfer for reconstruction of traumatic limb injuries in children. Microsurgery, 12: 207-215, 1991.

4- Chen H.C., Chuang C.C., Chen S., Hsu W.M. and Wei F.C.: Selection of recipient's vessels for free flaps to the 
distal leg and foot following trauma. Microsurgery, 15: 358-363, 1994.

5- Duteille F., Lim A. and Dautel G.: Free flap coverage of upper and lower limb tissue defects in children: A series of 22 patients. Ann. Plast. Surg., 50: 344-349, 2003.

6- Gharb B.B., Salgado C.J., Moran S.L., et al.: Free anterolateral thigh flap in pediatric patients. Ann. Plast. Surg., 66: 143-7, 2011.

7- Gilbert A.: Reconstruction of congenital hand defects with microvascular toe transfers. Hand Clin., 1: 351-60, 1985.

8- Lin C.H., Mardini S., Lin Y.T., Yeh J.T., Wei F.C. and Chen H.C.: Sixty-five clinical cases of free tissue transfer using long arteriovenous fistulas or vein grafts. J. Trauma, 56: 1107-1117, 2004.

9- Rinker B., Valerio I.L., Stewart D.H., Pu L.L. and Vasconez H.C.: Microvascular free flap reconstruction in pediatric lower extremity trauma: A 10-year review. Plast. Reconstr. Surg., 115: 1618-1624, 2005.
10- Serletti J.M., Schingo V.A. Jr., Deuber M.A., et al.: Free tissue transfer in pediatric patients. Ann. Plast. Surg., 36: 561-8, 1996.

11- Trost O., Kadlub N., Malka G., et al.: Microvascular free flap reconstruction in pediatric lower extremity trauma. Plast. Reconstr. Surg., 118: 570-1, 2006.

12- Van Landuyt K., Hamdi M., Blondeel P., Tonnard P., Verpaele A. and Monterey S.: Free perforator flaps in children. Plast. Reconstr. Surg., 116: 159-169, 2005.

13- Yazar S. and Lin C.H.: Selection of recipient's vessel in traumatic lower extremity. J. Reconstr. Microsurg, 28: 199-204, 2012.

14- Cherubino, Mario, et al.: "Muscle versus fasciocutaneous flap in lower limb reconstruction: Is there a best option?." Journal of Reconstructive Microsurgery, 33.S 01: S27S33, 2017.

15- Paro, John, Grace Chiou and Subhro K. Sen: "Comparing Muscle and Fasciocutaneous Free Flaps in Lower Extremity Reconstruction-Does It Matter?." Annals of Plastic Surgery 76: S213-S215, 2016. 